\title{
Middle School Physics Experiment Teaching Within "Internet Plus": From the Status Quo to Implications
}

\author{
Yi Chen \\ Correspondence: Yi Chen, College of Physics and Optoelectronic Engineering, Shenzhen University, Shenzhen, \\ 518060, Guangdong, China.
}

Received: November 2, 2021

Accepted: December 6, 2021

Online Published: December 12, 2021

doi:10.11114/jets.v10i2.5421

URL: https://doi.org/10.11114/jets.v10i2.5421

\begin{abstract}
Middle school physics experiment is a significant basic course with extensive content and strong practicability. This course has high requirements for students to master and understand the background and basic principles of various physical experiments, as well as the working principles and the use of various experimental devices. Based on the importance of physics experiment teaching and the limitations of the traditional experiment teaching mode, this paper first reviews the traditional mode in the context of the Internet and puts forward the new physics experiment teaching mode within "Internet Plus" in the new era, including theoretical guidance of constructing the experimental teaching mode, the innovation of teaching methods and examination methods, and the prospect of promoting the development of education industry. At the same time, this paper puts forward the network teaching platform system that can implement the new physics experiment teaching, including exercises, flipped classroom, and Massive Open Online Courses (MOOC), and discusses them separately, hoping to provide research reference for middle school physics teaching and research in the future.
\end{abstract}

Keywords: middle school physics experiment teaching, "Internet Plus", teaching mode, new operation platform

\section{Introduction}

Physics and experiment teaching are closely related. On the one hand, physics is an experiment-based science, and the discovery of physical laws depends on physical experiments (cf. Su et al., 2009; Huang \& Fu, 2018). On the other hand, experimental teaching has outstanding advantages in cultivating students' active learning, hands-on ability, and innovative consciousness (Wang et al., 2006). As a critical basic course, the middle school physics experiment aims to guide students to be familiar with the historical sources and principles of each physical experiment. Experiments can also help students to train students to think independently, consult materials, and determine experimental principles and methods (cf. Wen et al., 2021; Zhao et al., 2015; Li \& Liu, 2017). However, the current traditional middle school physics experiment teaching is limited by space and time. According to the latest research, with the rapid development of the Internet, the effective use of the Internet can effectively remedy its shortcomings.

The combination of "Internet Plus" and physics experiment teaching mode can realize the teaching innovation. The socalled "Internet Plus" refers to the process of diffusion, application, and deep integration of the new generation of Internetbased information technologies (including mobile Internet, cloud computing, Internet of Things, big data, etc.) in various sectors of economic and social life (Wang, 2016; Li \& Liu, 2017). Its essence is the online and digitalization of traditional industries (Ning, 2015). "Internet Plus" means the integration and transformation of traditional industries with Internet technology, which results in the emergence of this new industrial form $(\mathrm{Xu}, 2015)$. At present, education is generally considered to be the most concerned field in the future Internet industry. The rapid development of "Internet Plus" has brought new opportunities to the reform of basic education, which can give teachers new insight and optimization ability to teach (Shang et al., 2018; Luo et al., 2019). Its deep integration with education has injected new vitality into the education circle, changed the traditional teaching mode, and stimulated the learning intention of a higher level (Xie, 2017). For middle school physics experiment teaching, the new physics experiment teaching mode within "Internet Plus" is more likely to make teaching and learning activities closely combined with the Internet, so as to break through the old restrictions (Li \& Liu, 2017).

This paper starts from the limitations existing in the traditional physics experiment teaching mode and analyses the new physics teaching mode and the operating platform of the new physics experiment teaching mode within "Internet Plus". 
After commenting on the traditional physics experiment teaching model and extending it to the limitations of current physics teaching, this paper focuses on the new teaching platform within "Internet Plus", further discusses the new physics experiment teaching mode, and puts forward some suggestions on the future middle school physics teaching experiment and research.

\section{Limitations of the Traditional Physics Experiment Teaching Mode}

\subsection{The Teaching Mode of Physics Experiment}

\subsubsection{The Individual Needs of Students}

In physics experiment teaching, individualized learning can maximize students' learning efficiency. Individualized learning emphasizes that teachers should respect the differences of every individual student. Students are encouraged to carry out autonomous, discovery, and exploration learning in a student-centered or student-oriented pattern, which helps them to build a knowledge framework, and enables them to be more actively involved in classroom learning (Tang et al., 2021). In the 1960s, Linsley also proposed the concept of precision teaching based on operational reflexive principle (Lei \& Zhu, 2016; Luo et al., 2019). At present, blended learning is put forward based on the rapid development of the Internet, with its original intention to combine the network with the traditional way of learning to create e-learning. Teachers should not only guide, inspire and monitor the teaching process as a leading role, but also fully motivate students to take initiative, and show enthusiasm and creativity in learning (He, 2003; Ding, 2016). Research on blended learning also reveals the important role of individualized learning in physics teaching to a certain extent. As for physical experiments, students will also produce individualized design, operation, conclusion, and so on in the process of the experiment. Therefore, there is inevitability and urgency in the implementation of individualized physics experiment teaching for students (Luo, 2019; Tang \& Liang, 2021) to promote the effectiveness and efficiency of their learning.

Physics experiment teaching is often difficult to achieve accurate teaching according to the aptitude of students. Firstly, the "teacher-centered" mode in middle school physics experiment teaching is quite common (Li, 2011; Li \& Liu, 2017); that is, students' learning progress is almost dominated and regulated by teachers. Secondly, due to the different knowledge bases and thinking abilities, their performance in each experiment will be different (Tang \& Liang, 2021). Therefore, teachers cannot accurately understand and grasp the learning status and changes of students, but can only organize teaching according to the level of most students (Luo et al., 2019). In the traditional physics experiment teaching mode, teachers cannot timely understand students' experimental conditions based on the diagnostic evaluation of personalized information such as students' interests, hobbies, abilities, existing experience, and knowledge on the Internet (Tang et al., 2021). In experimental teaching design, as the starting point of teaching, teachers can only carry out learning situation analysis based on teaching experience and observation of students. Analysis of such learning is subjective, not accurate, which could result in the fact that teachers only focus on the experiment content and choose teaching strategies that cannot be effectively applied to the actual situation of students. Therefore, classroom teaching can only be carried out for most students, leading to a large difference in the level of students in a teaching class. Meanwhile, teachers are unable to provide comprehensive and targeted guidance and to help for students' various pre-concepts, myths, learning problems, and difficulties in physics experiments (Luo et al., 2019).

The traditional teaching and evaluation method of physics experiments has great disadvantages (Li \& Liu, 2017). Hybrid teaching design, learning analysis, and measurement have always been the focus of higher education research. Even so, traditional physics experiment teaching still has many limitations in learning follow-up and academic evaluation of physics middle school experiments. For example, in terms of analysis and accurate evaluation, most schools adopt the traditional way of physical experiment evaluation. The final score is obtained based on the experimental report submitted by students for each experiment, but they do not pay much attention to the operation process of students in the experiment, showing that teachers cannot accurately grasp the learning situation of students. This evaluation method cannot truly reflect the experimental level of students, nor can it accurately reflect their individual scientific research innovation ability, and it is difficult to stimulate students' creative thinking and experiment enthusiasm (Li \& Liu, 2017). As a whole, the evaluation method of traditional physics teaching is still in the developing stage, so it is necessary to further study and explore the evaluation method.

\subsubsection{The Experimental Teaching Concept and Mode}

At present, the teaching concept of physics experiments in middle school is lagging. The existing physics experiment teaching is mostly situated in the traditional teaching mode, and the mixed learning mode is rarely used. The common blended learning mode should be a mixture of various teaching resources, learning environment, presentation means, and learning methods (Xue, 2014). Research on the application of blended learning in physics teaching is only conducted currently on the conceptual surface. Although both the concept and characteristics of blended learning are given, in the application, especially in the preparation, lecture, practice, and evaluation of physics classroom teaching, it only gives some descriptions which are similar to those within traditional teaching (Tai, 2011; Ding, 2016), or just the idea of hybrid 
learning in a simple network environment (Zhang \& Wang, 2011; Ding, 2016), which is not conducive to the development of the current physics experiment teaching mode into a more advanced form.

At present, the reform of physics experiment teaching mode is still in the exploring stage. On the one hand, the establishment of a mature teaching mode not only involves theoretical guidance, but also needs repeated verification and summary in practice, and the teaching stage of high school physics experiment under the new curriculum concept is still not enough to establish a mature teaching mode. From another angle, most elements in the traditional teaching mode are still not unified and complete in combination with the teaching model of high school physics experiments and are in the "running-in forming period" (Li et al., 2013). In the experimental class, due to the limitation of class time, teachers may pay more attention to the operation process, and just make a simple introduction to the theoretical knowledge. In this teaching mode, some abstract and complex physical concepts prevent students from obtaining complete perceptual materials, which is easy to cause perceptual barriers and fail to achieve good teaching effects (You et al., 2013). High school physics experiment teaching mode is too much based on experimental types of classification research, but in the actual teaching situation, it is specific, with overlapping problems, the flexible use of mode, such as three modes of high school physics experiment teaching at present, namely "exploratory experiment", "open experiment" and "computer-aided experiment" ( $\mathrm{Li}$ et al., 2013). While the current physics experiment teaching mode presents the trend of continuous innovation, the overall operation is still not mature enough.

\subsection{The Effectiveness of Physics Experiment Teaching Resources}

\subsubsection{Experimental Environment}

It is sometimes difficult to accurately create an experimental environment in the middle school physics experiment course. For some high school teaching at the present stage, limited resources such as capital, manpower, and space make it difficult for physics experimental equipment to meet the requirements of physics teaching and then affect the learning effect of students. Under the influence of the new curriculum reform, the experimental resources in high school physics are also constantly improved, but the analysis of the existing physics experiment teaching shows that the current physics experiment is far from meeting the teaching requirements. From some specific performance, the lack of equipment and laboratory hardware configuration, to a great extent, affects the development of some physical experiments. Even if some schools are equipped with experimental equipment, the effect of experimental teaching cannot meet the requirements of teaching due to the influence of outdated and aging equipment, directly influencing the teaching effect.

\subsubsection{Experimental Resource Utilization Efficiency}

The waste of physics experiment teaching resources is not uncommon in middle schools. Multimedia technology of modern educational methods has a series of advantages especially an abundance of information (cf. Jiang \& Xiao, 2009; Yu, 2009; Ruan, 2010; Zhang et al., 2010; Ma, 2010; You et al., 2013). Although in physics experiment course teaching, classroom efficiency can be significantly improved through the assistance of multimedia technology simulation experiments (You et al., 2013; Jiang, 2006; Wang, 2007; Chen et al., 2016), it cannot replace real experimental teaching. Some experimental classes in middle schools simply use multimedia to demonstrate the experimental process rather than give students opportunities to operate the equipment on their own, which undoubtedly reduces the utilization frequency of laboratories. For high school physics teaching, the laboratory plays a cardinal big role, but in some high schools, labs are not effectively managed and used, and some of them are outdated or depreciated. As the laboratory cannot be effectively utilized, there are "overcapacity" and other related problems in teaching, and it is thus difficult to ensure the effective utilization of physics experiment teaching resources in middle school (Li \& Liu, 2017).

Students are sometimes unable to absorb theoretical knowledge efficiently through operational experiments. Since physics experiment is flexible and knowledge is interlinked, simply focusing on a certain aspect of the experiment teaching cannot affect the overall situation in the high school physics experiment teaching. In view of the problems existing in the high school physics experiment teaching, most of the strategies or suggestions given tend to solve a certain problem. Such problems are not deepened or related to physics experiment teaching in school or even to physics teaching as a whole ( $\mathrm{Li}$ et al., 2013). In addition, because of the limitation of the traditional high school physics teaching mode, it is difficult to strike a balance between experimental and theoretical teaching, so the theoretical teaching and experimental teaching are not generally synchronized (You et al., 2013). In the whole teaching process, students will lose interest and initiative in learning once they are unable to efficiently absorb knowledge or immediately understand the value brought by the learning process (You et al., 2013). It can be seen that the traditional teaching model of physics experiments still has some limitations, which means innovation should be made through the proper use of the Internet. 


\section{The "Internet Plus" Physics Experiment Teaching Mode}

\subsection{The Implementation of "Internet Plus" Physics Experiment Teaching Mode}

\subsubsection{Establish Specific Theoretical Guidance and Teaching Objectives of Each Experiment}

The new physics experiment teaching mode aims to establish the main teaching task according to the new teaching demand. The so-called new physics experiment teaching mode is student-centered based on the Internet. This teaching mode also advocates diversity in physics experiment teaching and autonomy in learning, updates ideas in physics experiment teaching evaluation, and actively promotes the overall development of students' experimental quality. Physics experiment courses require students to learn physics-related concepts through experiments and understand the development of experiments, and the impact on social development. Students are also required to pay attention to the connection between physics and other disciplines and the application of physics and master the basic experimental skills of physics. It is of great help to cultivate students' scientific inquiry ability, independent learning ability, practical ability, innovation ability, independent research ability, and problem-solving ability, which can mobilize students' enthusiasm for practice, stimulate their interest in learning, exercise their ability of cooperation and communication, and correct students' scientific attitude. It also works to inspire students' scientific spirit and attach great importance to students' scientific literacy ( $\mathrm{Li}$ et al., 2013). On the other hand, the online learning environment can maximize the initiative and enthusiasm of students and realize individualized learning (Deng, 2012). Different levels of students can have their individualized learning content and their own mode of learning (Huai, 2010). Only by fully considering the individual differences between students, after knowing that traditional experimental teaching mode does not fit in with actual demand, can active and autonomous learning be made possible. Students should be given the initiative to learn and create learning-centered teaching concepts (Hu \& Fan, 2012; Huang \& Fu, 2018).

The new physical experiment teaching mode intends to check the experimental conditions of each experiment and establish the operating procedures. First of all, for the presentation of teaching resources to students, it is necessary to build an experimental teaching and resource service platform supported by "cloud computing" technology. This mode provides users with a large number of resources required to construct experimental teaching and services through the Internet, without downloading or installing resources locally, so as to realize the networking, virtualization, and integration of experimental teaching and services, optimize the experimental teaching environment and deploy it on the cloud environment. In this regard, it manages to break the limitations of existing experimental conditions and environment and solve the problem of insufficient experimental resources (cf. Lin, 2011; Ge et al., 2014; Li \& Liu, 2017). Furthermore, multimedia technology is also needed to make all the teaching courseware and handouts of physics experiment courses, which involve the fusion of text, graphics, images, audio, video and animation, and other media materials (Xiong \& Yao, 2012). If necessary, virtual reality technology is also needed, for some need intuitive present experiment contents of virtual simulation (Gao \& Zhang, 2013; Huang \& Fu, 2018), enabling students to intuitively understand experimental phenomena and gain theoretical knowledge. In addition, for the situation analysis of individualized learning, a teacheroriented mode needs to be established to collect data such as application of teaching resources, learners' characteristic information, and learning behavior, so as to provide an accurate basis for teachers' teaching intervention (Dyckhoff et al., 2012). It is also necessary to establish a data analysis library that can integrate the data of learners and courses, make learning predictions, interventions, and adjustments based on the above data (Han \& Cheng, 2018), and present the calculated results to learners. Next, in order to realize convenient and efficient interactive communication, it is necessary to use Web programming technology and database technology (Zhao et al., 2006) to build a network interactive teaching system integrating course arrangement, course appointment, score management, online communication, online examination, and educational administration management (Li \& Liu, 2017; Huang \& Fu, 2018).

\subsubsection{Realize the innovation of teaching mode}

It is necessary to establish the principal position of students in teaching for the innovation of teaching mode. The experimental data measured by students can be transmitted to teachers in real-time through the network, so that they can know the progress of each student's experiment in time, check the experimental data in real-time, store the experimental records, and finally get the corresponding experimental results (cf. Zhu, 2011; Zhou, 2012; Chen \& Wang, 2016; Li \& Liu, 2017). "Internet Plus", therefore, makes the new teaching mode widely used to support many other kinds of new teaching modes based on the Internet platform, such as new exercises teaching mode, MOOC network curriculum mode that greatly expand the function and value of high-quality education resources. Such development enables students to break the limitation of space and time and carry out classroom learning anytime and anywhere (Zheng, 2017).

The physics exercise teaching mode within "Internet Plus" is beneficial to ensure the quality of students' individualized development. First of all, it is believed that experiment teaching is an essential part of physics teaching and science teaching, and students must carefully complete the carefully set experiments in physics (Liu, 2016). Efficient experiment teaching can cultivate students' ability to solve problems on their own so that students can flexibly apply the theoretical 
knowledge they have learned to solve problems and achieve self-breakthrough and development, which has a very important influence on the improvement of the quality of physics teaching (cf. Wang et al., 2007; Wang, 2016; Zheng, 2017). Secondly, the formation of concepts and laws in physical experiment teaching is a process of induction and abstraction. The teaching system based on the Internet platform can effectively help students to complete this complex cognition process, and fully cultivate their physical thinking ability, physical learning, and research ability in the construction, comprehension, and application of physical concepts and laws (Zheng, 2017).

Based on the requirements of high school physics curriculum standards and the characteristics of physics subjects, it is of great significance to combine experiment teaching with practical operation. Due to the limitation of class time and hardware resources, the traditional high school physics teaching process often cannot provide students with careful observation of physical phenomena, so it is more difficult to analyze the cause of the appearance of physical phenomena (Zheng, 2017). The Internet learning platform and the use of multimedia teaching resources can break these limitations. First of all, during the teaching of physics concepts and laws, teachers can put relevant experimental videos taught in class on the Internet in advance, and students can ask and discuss with each other during the watching process, and participate in the solution, so as to realize information interaction and resource sharing (Zheng, 2017). Secondly, in terms of pre-class preview or after-class review, teachers can form a modular teaching design system by reasonably arranging teaching practices in each link. The topic is classified into several parts according to the topic type, and each part is recorded into a short teaching video, and then uploaded to the Internet for students to watch in advance to deepen their understanding of the characteristics of the experimental question type. Also, the corresponding topic is arranged according to the classification. In this way, students can clearly understand the overall framework of the question type and the possible direction of the proposition and sort out the corresponding problem-solving ideas, to achieve efficient problem solving and comprehensive development of effective teaching. Finally, after the experiment training, the system can make an evaluation according to students' answers or test results. Through the data and evaluation results of the system, students can know how well they have mastered physical concepts and laws, and teachers can clearly know how well students have gained the skill in real time (Zheng, 2017).

The realization of effective sharing of learning resources requires the establishment of a physical experiment database with high mobility. The platform can effectively integrate experimental resources to improve the closure and limitation of traditional experimental teaching mode, realize the optimal allocation of resources, and improve the use efficiency (Xu \& Hao, 2015). Resource platform provides a more convenient way, using "cloud computing" technology to access, collect, sort out all kinds of experimental teaching materials and courseware so that all the teachers and students in the process of experiment teaching can constantly update, improve, and enrich the teaching resource. In this way, an open and sustainable ecological environment of experimental teaching resources can be constructed to better realize the optimal utilization of resources (Li \& Liu, 2017), and finally, a computer database can be established to achieve the co-construction and sharing of problem-based high school physics experimental teaching resources (Li et al., 2013).

\subsubsection{Evaluate Experimental Process and Innovate Experimental Examination}

The individualized evaluation of the new physics experiment teaching mode must be carried out offline and online accurately. In form, blended learning means that students learn online independently or according to the requirements of teachers, which is basically consistent with online self-study in MOOC. The difference lies in that the evaluation of MOOC is completely online, while the evaluation of hybrid learning and teaching are mainly conducted offline, and interactive learning is conducted in class with corresponding teachers and students (Men et al., 2015; Ding, 2016). This is the "Internet Plus" blended learning under the support of the mode, where the physical experiment teaching can be used as online and offline evaluation, formative evaluation, and summative evaluation (Guo et al., 2016). This mode combines the teachers and students at ordinary times in online interactive situations, to give students daily evaluation experiments, summary, and online evaluation grades again, offline evaluation adopts the combination of students' experimental classroom performance and experimental class examination (Li \& Liu, 2017). This combination of online and offline evaluation will promote accuracy.

In addition to the online and offline evaluation methods, experimental evaluation methods can also be innovated in other aspects. It is hypothesized that in after-class reflection, teachers can introduce a common example in real life and ask questions through a question-oriented online opening with a vivid popular science picture related to experimental content, so as to attract students' attention and improve their interest in scientific research and exploration (Zhao et al., 2016). Scientific research innovation is one of the ultimate training objectives of experiments. If students can put forward innovative ideas, they can be given appropriate bonus points. Such a diversified assessment mechanism can not only ensure the objectivity and fairness of evaluation, but also fully stimulate students' enthusiasm for experiments (Zhao, 2016), and cultivate students' divergent thinking, innovative thinking, and scientific research ability (cf. Zhang, 2014; Wang et al., 2015; Xie, 2017). 


\subsection{The Prospect of "Internet Plus" Physics Experiment Teaching Mode}

\subsubsection{Innovation}

The physics experiment teaching mode within "Internet Plus" has changed the traditional way of experiment preview and teacher-student communication. Teachers can accurately judge the teaching effect through the test data of students and conduct teaching reflection based on empirical data. Students also use the data to judge how well they are learning. In addition to the revision and review of experimental reports, various chat systems, network videos, e-mails, experimental forums, network classrooms and so on also provide convenient channels for communication between students and teachers, making communication no longer constrained by time and space, becoming freer, more open and more timely, especially for designing experiments in the lab when students encounter problems. The application of modern information technology contributes to the timely communication and exchange between teachers and students, gets problems solved in time, which is helpful to the deep understanding of the experiment, thus improving the learning efficiency (cf. Dong, 2016; Wang et al., 2016; Xie, 2017; Huang \& Fu, 2018). The interaction between teachers and students combined with the online classroom allows students to get more targeted and individualized learning guidance than traditional teaching. In this process, teachers and students communicate with each other, so as to achieve consensus, sharing, and common progress (cf. Wu et al., 2010; You et al., 2013; Huang \& Fu, 2018; Luo et al., 2019).

Internet technology improves the efficiency of physics experiment teaching, which is also reflected in the innovation of the teaching mode. In the traditional concept of some logical and critical subjects, it seems that teachers need to have more on-site interactions with students and mobilize students' emotions to ensure the quality of teaching. in the process of physics teaching, students' abilities to accept information and the speed of reaction are not consistent, with some of them lagging on occasion, so the teaching effect is not ideal. As for the teaching mode on the network platform, students can adjust the speed of the course video, pause in the place where they cannot react, move forward in the place they already understand, and even watch the playback. Research shows that new Internet physics experimental teaching modes with the flipped classroom and hybrid teaching can achieve better results for highly reflective courses such as mathematics and physics (Wang \& Hu, 2018). In such a learning mode, there is a more equal teacher-student relationship, a more open learning environment, and more active students. Such a teaching mode is conducive to cultivating students' innovation ability and critical thinking ability.

\subsubsection{Efficiency}

Internet technology realizes high efficiency for physics experiment teaching. The rapid development and widespread use of modern information technology with computer multimedia and network as the core has greatly changed people's way of thinking and learning (cf. Xiong, 2012; Yang et al., 2014; Zheng, 2014). In the field of education, the application of information technology has changed the traditional teaching mode, enriched the teaching content, made the teaching method more flexible, and provided strong environmental conditions and technical support for the curriculum construction and teaching reform of colleges and universities (cf. Guo et al., 2002; Yang \& Gao, 2002; Qian, 2008; Xie \& Lan, 2011; Xu \& Yuan, 2011; Wang \& Xie, 2012; Wang et al., 2016). The present teaching resources on the network platform, through the demonstration experiment with the technology of multi-media to the physics experiment of organic, unify together, can break through the limitations of conventional instruments, make up for the shortage of the conventional instrument, and give full play to the advantages of information technology. As a supplement to conventional experiments, it helps students to discover rules, acquire knowledge, improve their scientific, cultural quality, and experimental skills, and cultivate students' creative thinking and innovation ability (Li et al., 2010; Wu, 2011; You et al., 2013).

The new physics experiment teaching mode can be used in the experiment teaching network management- and application platform. The new physics experiment teaching network platform should be created, with the support of big data, which includes integrated laboratory management, experiment teaching management, and organization, student course selection system (courseware, report, etc.), teachers online educational administration system, the electronic lab resources, multimedia courseware, show website, and the information management platform, etc. Such network platform construction is not only convenient for the laboratory experiment teaching organization and management but advantageous to the mode, and the implementation of the open experiment teaching. These advantages make learning content from the extension to the classroom network and break through the experimental teaching of time, space, and the number of restrictions, greatly improving the experimental teaching effect (Wang et al., 2016; Zhang \& Ma, 2019). For example, teachers can choose students interested in the high and practical value of physics experiment course resources, such as practical technology disciplines, and build the knowledge system of fine courses, appropriate use of multimedia tools, which will practice cases released through the campus network to the platform for everyone to learn, to facilitate the students' autonomous learning (Wang \& Chen, 2019). 


\section{A New Physics Experiment Teaching Mode Platform}

\subsection{The Content of the Platform}

"Big data, cloud computing" has become an indispensable part of the new physics experiment teaching model. In the course of web-based teaching, the technology platform will accumulate a lot of log data. Finding and analyzing these data can provide more and more accurate evidence for teaching interventions, thus promoting learning, teaching, and management more effectively (Han et al., 2017; Han \& Cheng, 2018). For example, cloud computing technology can realize a variety of different convenience functions for different users, so as to better improve the quality and effect of physics experiment teaching (Wang et al., 2016). Specifically, according to the user types of the learning analysis platform, its applications can be further classified into learners, teachers, and managers. The learner-oriented application allows them to understand and reflect on the learning effect, analyze the learning process based on teaching principles, form individualized evaluation, provide learning suggestions, and promote individualized learning. The teacher-oriented application can support them to diagnose students' learning in time, design teaching interventions and adjust teaching strategies with the analysis results, and reflect on teaching methods and effects. The application for managers at different levels can promote the improvement of management efficiency and quality, support school education managers to evaluate the operation effect of the system, optimize decision-making plans, allocate resources reasonably, and change the management mode and effect of colleges and universities. Government managers can evaluate the operation of the whole higher education system according to the learning analysis model, and formulate policies for education quality assurance and efficiency improvement (Greller, 2012; Han \& Cheng, 2018). A fully functional network teaching platform must require highly sophisticated big data analysis to meet the individualized needs of users and form a positive interaction between online and offline (Li et al., 2012; Huang \& Fu, 2018).

Massive Open Online Course, an online teaching platform, is a good medium to run the new physics experiment teaching mode. First of all, MOOC courses are widely interactive and open and are a form of distance education. Such online courses emphasize knowledge construction, innovation, interaction, and collaboration between teachers and students, and individualized learning of learners (Wang \& Chen, 2019). In this learning mode, students can fully enjoy the convenience of "Internet Plus" and use mobile terminal devices at their fingertips to determine the time, progress, and method of learning without the limitation of time and space (Xie, 2017). In addition, the "traces" of information space left by all students online will be reflected in the database, and the concept and analysis methods of big data are widely used in MOOC, including data processing and monitoring of MOOC learners' performance (Yang, 2018; Wang \& Chen, 2019). At the same time, teachers can also make accurate learning situation analysis through the big data brought by the MOOC platform. Specifically, the online teaching platform can provide a variety of excellent experiment teaching resources and high quality online experimental teaching courses, which are not only beneficial to improve the influence of experimental physics teaching (Wang, 2016), but also create a physical experiment online study atmosphere through the new physics experiment teaching mode.

Secondly, the integration of flipped classrooms into MOOC teaching can form a hybrid teaching mode of "MOOC plus flipped classrooms" which is very close to the new physics teaching mode. A flipped classroom is where teachers reorganize teaching time inside and outside the classroom, students learn what is flipped after school, and the classroom becomes a place for teacher-student and pupil-student interaction (Wang \& Chen, 2019; Zhao, 2019). The innovative teaching mode of "MOOC+ Flipped classroom" uses new technological means to teach knowledge asynchronously (Zhang, 2019), leaving the traditional classroom time to students to lead and breaking the traditional teacher-centered form and highlighting students' dominant position in the classroom (Wang \& Chen, 2019). In this kind of hybrid teaching, experiment class-specific can be divided into stage mid import, practice, and evaluation stage three interrelated process (Chen \& Yang, 2015). Students can according to the actual needs of their time and their necessary and flexible learning, and in the subsequent offline with classmates in the classroom, teachers discuss problems (Hao \& Guo, 2016). This cooperative discussion mode creates space for students to create innovative design, train students to find and solve problems in experiments, not only consolidate experimental knowledge, but also integrate the knowledge of various disciplines (Zeng et al., 2015; Xie, 2017; Wang \& Chen, 2019).

\subsection{Suggestions on the Platform}

Individualized learning supported by multiple elements is effective within "Internet Plus", but there are still many limitations in practice. The following suggestions are raised in order to promote the efficient and orderly construction of new physics experiment teaching and further deepen the reform of practical teaching. First, efforts should be made to improve the teaching staff. It is very important to establish a reasonably structured, high-quality, and stable experimental team (Xiao, 2009). If there is no excellent experimental teaching staff in experimental teaching, improving the quality of practical teaching can only be an empty word. Therefore, it is necessary to increase the introduction of high-level experimental teaching talents, realize the improvement of the overall structure of the teaching staff, and equip high-level 
talents with high professional quality, rich theoretical knowledge, and practical experience (Yin, 2011; Tang et al., 2021). These talents can serve as the main lecturers of experimental courses. Second, there is a need to improve the teaching management mechanism. An innovative, efficient, and dynamic management mechanism can guarantee the physical experiment teaching mode and management innovation to the important source and power of harmonious development. Meanwhile, as for the use of offline laboratories, it is necessary to improve the regulations of operation and implement standardized management. (Xiao, 2009; Yin, 2011; Tang et al., 2021). Third, software construction should be strengthened. Software construction mainly includes development planning, routine management, talent training, experimental curriculum setting, and experimental teaching workflow, etc. Standardizing the construction of laboratory software will make the laboratory management gradually institutionalized and scientific. It can be seen on the whole that the new physics experiment teaching mode still needs to be improved and innovated.

\section{Concluding Remarks}

Within "Internet Plus", this paper systematically reviews and expounds middle school physics experiment teaching, including the limitations of traditional experimental teaching methods, the implementation of a new physics experiment teaching mode based on the innovation of network teaching platform system. It has been noticed that the Internet cannot be underestimated in terms of the ability to guide, as it does continue to bring great convenience to middle school physics experiment teaching The new mode involving, colorful flipped online classroom and point-to-point diversified individualized evaluation, is undoubtedly significant in cultivating students' comprehensive ability. The middle school physics experiment teaching mode and the rising network teaching platform within "Internet Plus" will become the trend of the future education industry progress. With the rapid development of the Internet in the education industry, the roles of teachers and students are constantly changing, and the teaching mode within "Internet Plus" is also accordingly improving. However, there are still unresolved problems in the operation of the network teaching platform. Future research can focus on specific physics experiment teaching theory and practice in the middle school, with the aim of exploring how to carry out basic middle physics experiment teaching through network teaching platform, and how to improve and develop the current teaching mode.

\section{Acknowledgements}

As the teaching assistant of Jialiang Chen, the author would like to express sincere thanks for his insightful suggestions and constructive feedback on content relevance, content sufficiency, organization, and language quality in an earlier version of this paper.

\section{References}

Chen, H., Shi, Y., \& Zhang, C. (2010). Discussion on the teaching mode of university physics demonstration experiment. Chinese Journal of Physics, 20(4), 95-99.

Chen, R., \& Yang, C. (2015). Research on hybrid learning mode design of SPOC. Chinese Journal of Distance Education, (5), 42-47, 67.

Chen, Z., \& Wang, Z. (2016). Research on laboratory opening mechanism based on innovative experimental project. Journal of Experimental Technology and Management, 33(1), 17-20.

Deng, X. (2012). Study on network learning system based on personalized guidance. Examination Week, (13), 112-113.

Ding, L. (2016). Hybrid teaching of secondary vocational physics based on "Internet +". China Electronic Education, (3), $141-145$.

Dong, Y. (2016). Discussion on interactive learning system based on Network. Journal of Laboratory Science, 16(4), 8082.

Dyckhoff, L., Zielke, D., Bultmann, M., Chatti, M. A., \& Schroeder, U. (2012). Design and implementation of a learning analytics toolkit for teachers. Journal of Educational Technology \& Society, 15(3), 58-76.

Gao, S., \& Zhang, T. (2013). Research on network interaction method of design based on 3D technology. Journal of Laboratory Science, 16(4), 83-85.

Ge, R., Zhu, Z., \& Wang, Y. (2014). Innovation and practice of laboratory management mode based on information platform construction. Journal of Experimental Technology and Management, 31(1), 15-18.

Greller, W., \& Drachsler, H. (2012). Translating learning into numbers: a generic framework for learning analytics. Educational Technology \& Society, 15(42), 42-57.

Guo, S., Gao, J., \& Li, Y. (2002). Education informatization, teaching methods under the condition of network information technology. Education Informatization, (12), 11-12.

Guo, Y., Guo, P., \& Zeng, H. (2016). Discussion on the evaluation of university physics experiment. Science and 
Technology World, (6), 125-126.

Han, X., \& Cheng, J. (2018). Construction and application of learning analysis model based on online teaching platform. Journal of Educational Research, 39(07), 33-39+48.

Han, X., Huang, Y., Ma, J., \& Cheng, J. (2017). A systematic review, analysis, and perspective of learning analysis. Tsinghua University Educational Research, (3), 41-51.

Hao, J., \& Guo, X. (2016). SPOC mode electrical experimental teaching under the background of Internet + . Laboratory Research and Exploration, 35(9), 209-213.

He, K. (2003). New Development of Educational Technology Theory through Blending Learning (I). Chinese Electronic Education, (3), 5-10.

Hu, J., \& Fan, Y. (2012). Web learning System design based on personalized recommendation technology. Journal of Software, (4), 47-50.

Huai, A. (2010). Design and development of interactive media learning system in campus. Information Technology, (10), 20-23.

Huang, J., \& Fu, W. (2018). Construction of comprehensive service platform of physics experiment Teaching Center network. Journal of Laboratory Research and Exploration, 37(5), 158-161.

Jiang, A., \& Xiao, J. (2009). Multimedia technology in college physics experiment teaching. College Laboratory Work Research, (2), 43-44.

Jiang, Y. (2006). The role of demonstration experiment in physics teaching. University Physics Experiment, 19(3), 111114.

Lei, Y., \& Zhu, Z. (2016). Precision teaching decision based on pre-learning data analysis. China Electronic Education, (6), 27-35.

Li, A., Ye, L., \& Zhang, Z. (2010). The reform of modern physics experiment teaching and the cultivation of college students' innovation ability. Journal of Laboratory Research and Exploration, 29(4), 77-78.

Li, G., Liu, C., \& Wang, J. (2013). Construction of "cloud" model in high school physics experiment teaching. Journal of Inner Mongolia Normal University (Education Science Edition), 26(6), 153-155.

$\mathrm{Li}, \mathrm{S}$. (2011). Some thoughts on the reform of university physics experiment teaching. Science and Technology Information, (5), 190.

Li, S., \& Liu, X. (2017). Construction of "Internet + " college physics experiment teaching system. Journal of Experimental Technology and Management, 34(1), 172-174.

Li, X., Zhang, H., \& Li, F. (2012). Discussion on the application of interactive teaching mode in general experimental teaching. College Laboratory Work Research, (3), 11-12.

Liang, H. (2011). On the teaching of high school physics exercises under the background of new curriculum, Middle school Teaching Reference, (05), 61.

Lin, Y. (2011). Innovation and practice of experimental teaching mode in universities under cloud computing environment. Journal of Laboratory Research and Exploration, 30(8), 272-274.

Liu, C. (2016). Optimization strategy of exercise teaching process in high school physics. Reference for Middle School Physics Teaching, (1-2), 30-33.

Luo, Q. (2019). Application research of personalized teaching based on big data analysis. Digital Teaching in Primary and Secondary Schools, (9), 9-12.

Luo, Y., Xie, X., \& Dong, S. (2019). Construction and practice of precision physics teaching classroom in junior middle school. Chinese Electronic Education, (1), 48-53.

Ma, L. (2010). The application and experience of multimedia teaching in college physics. Science and Technology Information, (13), 149-149.

Men, L., Wang, Z., \& He, B. (2015). The feasibility and concerns of MOOC localization. Modern Educational Technology, (25), 53-59.

Ning, J. (2015). Implementation background, connotation and main content of "Internet + " Action Plan. Electronic Government Affairs, (6), 32-36.

Qian, X. (2008). Information technology and teaching reform. Science and Technology Information, (10), 274. 
Ruan, Y. (2010). The application of multimedia technology in physics experiment teaching. Journal of Changchun University of Science and Technology (Comprehensive Edition), 5(2), 144-145.

Shang, C., \& Han, M. (2018). Design and research of online learning procedural evaluation system in the context of big data. China Electronic Education, (5), 90-95.

Su, X., Tang, J., \& Li, W. (2009). Design of physical virtual laboratory based on VRML technology. Journal of Experimental Technology and Management, 29(9), 67-69.

Tai, J. (2011). The application of hybrid learning concept in vocational school physics teaching. Vocational Education Expo, (6), 69.

Tang, A., \& Liang, Q. (2021). Personalized integration practice of high school physics experiment inquiry under the background of "Internet +". Physics Teaching, 43(3), 39-42.

Tang, L., Xie, G., \& Wu, D. (2021). The Exploration of personalized learning mode of junior middle school physics under the Background of Internet. Physics Teaching, 43(3), 36-38.

Wang, C., \& Hu, Y. (2018). Can flipped classroom really improve academic performance? -- A meta-analysis based on 38 experimental and quasi-experimental studies. Open Education Research, (4).

Wang, D., \& Chen, Y. (2019). Research on innovation of MOOC teaching mode in universities under the background of big data. Information Science, 37(11), 138-143.

Wang, G., Xie, B. (2012). A meta-analysis of learning and teaching styles under the condition of information technology. Modern Educational Technology, 22(3), 47-51.

Wang, H., Chen, Y., Sun, W., \& Zhang, L. (2016). Application of information technology in college physics experiment teaching. Journal of Experimental Technology and Management, 33(8), 141-144.

Wang, J., Wang, L., \& Li, Z. (2007). Optimization of physical exercise design using multimedia. Education Informatization in China, (10), 43-45.

Wang, S. (2016). Research on teaching strategies of senior high school physics exercises under the new curriculum standard. Scientific Chinese, (07), 315.

Wang, S., Song, W., \& Zhang, D. (2015). The mediating effect of deep learning on college students' curriculum learning experience and educational gain. Research on Audio-visual Education, (4), 90-94.

Wang, W. (2007). The role of demonstration experiment in physics teaching. Chinese Journal of Physics, 20(2), 84-85.

Wang, X., Li, J., \& Tan, Z. (2016). Development status and future trend of network technology facing "Internet +". Journal of Computer Research and Development, 53(4), 729-741.

Wang, Z., Liu, G., \& Wu, Y. (2006). Strengthening engineering practice teaching to cultivate students' engineering practice and innovation ability. Journal of Hefei University of Technology (Social Science edition), (4), 1-5.

Wen, J., Yang, X., \& Liu, T. (2021). Creating a new teaching system of college physics experiment course. University Physics Experiment, 25(10), 89-91.

Wu, R. (2011). Innovative physics experiments and the cultivation of students' innovative ability. Journal of Laboratory Research and Exploration, 30(7), 80-81.

Wu, X., Wang, X., \& Liu, Y. (2010). Training of engineering literacy and innovation ability based on practical training teaching. China Electric Power Education, (30), 133-134.

Xiao, L., Liu, H., \& Zhang, Y. (2009). Strengthening the construction of experimental Teaching center and constructing innovative education System. Journal of Laboratory Research and Exploration, 28(01), 26-28+41.

Xie, A., Luo, S., \& Kong, Y. (2017). Exploration on flipped teaching of SPOC physical chemistry experiment. Journal of Experimental Technology and Management, 34(9), 211-214.

Xie, H., \& Lan, X. (2011). Reform of university physics experiment teaching by using modern information technology. Examination Week, (62), 22-23.

Xiong, C., He, X., \& Wu, R. (2012). On the revolutionary impact of information technology on education development. Educational Research, (6), 22-29.

Xiong, Y., \& Yao, J. (2012). Development of virtual experiment system for online simulation of physical chemistry. Chemical Engineering Higher Education, (1), 26-29.

Xu, X., \& Hao, D. (2015). The construction of university physics and experimental resources under THE MOOC 
environment. Journal of Xi' 'an Aeronautical Institute, 33(1), 94-96.

$\mathrm{Xu}, \mathrm{X} .$, \& Yuan, H. (2011). Application of computer and network technology in open experiment teaching of university physics experiment. Science and Technology Information, (29), 116.

$\mathrm{Xu}, \mathrm{Z}$. (2015). Innovation and opportunity analysis of traditional industries in the Era of "Internet +". Internet World, (5), $1-4$.

Xue, Q. (2014). Application of blended learning mode in biology teaching of junior middle school. Art of Teaching, (12), 15.

Yang, B. (2018). Research on teaching mode of vocational education based on MOOC in the context of big data. Science and Technology Innovation Guide, (22), 205-208. https://doi.org/10.12783/dtssehs/icems2018/20091

Yang, C., \& Gao, L. (2002). On the consensus of interactive process of distance teaching under the condition of information technology. China Electronic Education, (11), 59-62.

Yang, Z., Yang, H., \& Wu, D. (2014). On the deep integration of information technology and contemporary education. Educational Research, (3), 88-95.

Yin, X., Xue, Y., Wen, J., Zhang, B., \& Liu, X. (2011) Learning from the experience of famous universities to accelerate the construction of experimental center platform. Journal of Experimental Technology and Management, 28(08), $212-214+217$.

You, S., Wu, L., Cai, B., \& Shi, X. (2013). Application of multimedia in modern physics experiment teaching. Journal of Laboratory Research and Exploration, 32(6), 326-328.

Yu, J. (2009). On the application of multimedia technology in physics teaching. Science and Technology Information, (6), 168-168.

Zeng, M., Li, G., \& Zhou, Q. (2015). From MOOC to SPOC, the construction of a deep learning model. China Electronic Education, (11), 28-34, 53.

Zhang, B., \& Wang, Q. (2011). Application of blended learning concept in physics teaching. Science, Chemistry and Biology Teaching and Research, (8), 180.

Zhang, G. (2014). Review of e-learning environment deep Learning research in China. Modern Distance Education, (5), 60-67.

Zhang, H., \& Ma, Y. (2019). A review of research on physics education and Teaching in middle school in 2018 -- Based on an analysis of the republication of the paper "Physics Teaching and Learning in Middle School". Physics Teacher, 40(2), 2-6.

Zhang, K. (2019). Research on MOOC teaching mode construction in the era of big data. Journal of Information Record Materials, (2), 150-151.

Zhang, R., Wang, Z., Gu, M., \& Xie, S. (2017). The process and trend of college physics teaching reform under the "Internet +" environment. College Teaching in China, (2), 64-67.

Zhang, S., Liu, H., \& George. (2010). Application of multimedia technology in college physics teaching. China Science and Technology Information, (14), 261-262.

Zhao, J. (2019). Research on flipped classroom teaching mode of foreign language under MOOC environment. China Modern Educational Equipment, (2), 112-113, 120.

Zhao, L., Wang, X., \& Fan, H. (2015). Discussion on the digital and network teaching reform of university physics experiment. Chinese Journal of Physics, 28(1), 113-114.

Zhao, Y., Li, R., \& Zhang, W. (2006). The construction of university experiment Center website based on Web. Bioinformatics, (1), 16-18.

Zhao, Y., Li, X., \& Cui, J. (2016). The cultivation of students' innovation ability in basic experimental teaching under MOOC environment. Journal of Experimental Technology and Management, 33(3), 13-15.

Zheng, X. (2017). Construction strategy of "Internet +" physics exercise teaching. Teaching and Management, (22), 6870 .

Zheng, Y. (2014). Research on personalized Learning of College students under information technology environment. China Electronic Education, (7), 126-132.

Zheng, Y. (2017). Principles of physics exercise design based on Internet platform. Physics of Middle School (High School Edition), 35(5), 29-30. 
Zhou, H. (2012). Design of university Laboratory Information Management System. Intelligent Processing and Applications, (6), 77-81.

Zhu, Y. (2011). Building an open innovation laboratory to train innovative talents. China Modern Educational Equipment, (13), 46-47.

\section{Copyrights}

Copyright for this article is retained by the author(s), with first publication rights granted to the journal.

This is an open-access article distributed under the terms and conditions of the Creative Commons Attribution license which permits unrestricted use, distribution, and reproduction in any medium, provided the original work is properly cited. 